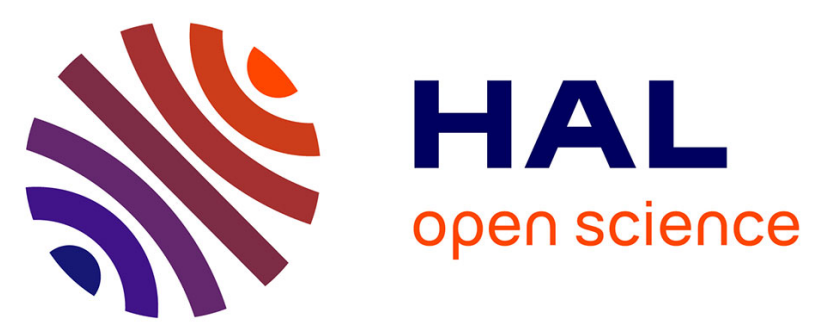

\title{
Core phosphine-functionalized amphiphilic nanogels as catalytic nanoreactors for aqueous biphasic hydroformylation
}

Emeline Lobry, Andrés Fernando Cardozo Perez, Laurie Barthe, Jean-François Blanco, Henri Delmas, Si Chen, Florence Gayet, Xuewei Zhang, Muriel Lansalot, Franck D'agosto, et al.

\section{To cite this version:}

Emeline Lobry, Andrés Fernando Cardozo Perez, Laurie Barthe, Jean-François Blanco, Henri Delmas, et al.. Core phosphine-functionalized amphiphilic nanogels as catalytic nanoreactors for aqueous biphasic hydroformylation. Journal of Catalysis, 2016, 342, pp.164-172. 10.1016/j.jcat.2016.07.023 . hal-01878788

\author{
HAL Id: hal-01878788 \\ https://hal.science/hal-01878788
}

Submitted on 21 Sep 2018

HAL is a multi-disciplinary open access archive for the deposit and dissemination of scientific research documents, whether they are published or not. The documents may come from teaching and research institutions in France or abroad, or from public or private research centers.
L'archive ouverte pluridisciplinaire HAL, est destinée au dépôt et à la diffusion de documents scientifiques de niveau recherche, publiés ou non, émanant des établissements d'enseignement et de recherche français ou étrangers, des laboratoires publics ou privés. 


\section{Open Archive TOULOUSE Archive Ouverte (OATAO)}

OATAO is an open access repository that collects the work of Toulouse researchers and makes it freely available over the web where possible.

This is an author-deposited version published in : http://oatao.univ-toulouse.fr/ Eprints ID : 20831

To link to this article: DOI : /10.1016/j.jcat.2016.07.023

URL : https://doi.org/10.1016/j.jcat.2016.07.023

To cite this version : Lobry, Emeline $\rightleftharpoons$ and Cardozo Perez, Andrés Fernando $כ$ and Barthe, Laurie

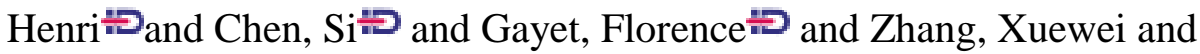
Lansalot, Muriel and D'Agosto, Franck and Poli, Rinaldo Eric $\leftrightarrows$ and Julcour-Lebigue, Carine amphiphilic nanogels as catalytic nanoreactors for aqueous biphasic hydroformylation. (2016) Journal of Catalysis, 342. 164-172. ISSN 00219517

Any correspondence concerning this service should be sent to the repository administrator: staff-oatao@ listes-diff.inp-toulouse.fr 


\title{
Core phosphine-functionalized amphiphilic nanogels as catalytic nanoreactors for aqueous biphasic hydroformylation
}

\author{
Emeline Lobry ${ }^{\mathrm{a}, 1}$, Andrés F. Cardozo ${ }^{\mathrm{a}, 2}$, Laurie Barthe ${ }^{\mathrm{a}}$, Jean-François Blanco ${ }^{\mathrm{a}}$, Henri Delmas ${ }^{\mathrm{a}}$, Si Chen ${ }^{\mathrm{b}}$, \\ Florence Gayet ${ }^{\mathrm{b}}$, Xuewei Zhang ${ }^{\mathrm{c}, 3}$, Muriel Lansalot ${ }^{\mathrm{c}}$, Franck D’Agosto ${ }^{\mathrm{c}}$, Rinaldo Poli ${ }^{\mathrm{b}, \mathrm{d}, *}$, Eric Manoury ${ }^{\mathrm{b}, *}$, \\ Carine Julcour ${ }^{\mathrm{a}, *}$ \\ ${ }^{a}$ Laboratoire de Génie Chimique, Université de Toulouse, CNRS, INPT, UPS, 4 Allée Emile Monso, BP 84234, 31432 Toulouse, France \\ ${ }^{\mathrm{b}}$ CNRS, LCC (Laboratoire de Chimie de Coordination), Université de Toulouse, UPS, INPT, 205 route de Narbonne, BP 44099, 31077 Toulouse Cedex 4, France \\ ${ }^{\mathrm{c}}$ Université de Lyon, Univ. Lyon 1, CPE Lyon, CNRS, UMR 5265, C2P2 (Chemistry, Catalysis, Polymers É Processes), Team LCPP, 43 Bd du 11 Novembre 1918,69616 Villeurbanne, France \\ ${ }^{\mathrm{d}}$ Institut Universitaire de France, 103, bd Saint-Michel, 75005 Paris, France
}

\begin{abstract}
A B S T R A C T
Amphiphilic phosphine-functionalized nanogel particles were synthesized by aqueous polymerizationinduced self-assembly insuring a well-defined architecture as well as a narrow size distribution (average diameter of ca. $90 \mathrm{~nm}$ in water). They were successfully applied as ligands for the biphasic hydroformylation of 1-octene catalyzed by rhodium, yielding TOFs in the $350-650 \mathrm{~h}^{-1}$ range and a linear to branched aldehyde ratio of 3.5. Embedding the phosphine ligands within a cross-linked structure did not strongly impede mass transfer toward the active centers, as proved by fast metal coordination and a catalytic activity tantamount to that of higher chain mobility micelles or core-cross-linked micelles that have phosphine moieties located on flexible linear arms. However, this extended cross-linking reduced particle swelling and transfer to the organic phase, affording a significantly lowered Rh loss. For all the architectures, a low functionalization degree was preferable to achieve high activity, the selectivity remaining essentially unchanged.
\end{abstract}

\section{Introduction}

Olefin hydroformylation is the World's largest industrial process making use of homogeneous catalysis, with an annual production volume in excess of 12 Mton [1-4]. This topic continues to

Abbreviations: ACPA, 4,4'-azobis(4-cyanopentanoic acid); CCM, core-crosslinked micelle; CTPPA, 4-cyano-4-thiothiopropylsulfanyl pentanoic acid; DEGDMA di(ethylene glycol) dimethacrylate; DPPS, 4-diphenylphosphinostyrene; M, micelle; MAA, methacrylic acid; NG, nanogel; PEOMA, poly(ethylene oxide) methyl ether methacrylate; S, styrene; TPP, triphenylphosphine.

* Corresponding authors at: CNRS, LCC (Laboratoire de Chimie de Coordination) Université de Toulouse, UPS, INPT, 205 route de Narbonne, BP 44099, 31077 Toulouse Cedex 4, France (R. Poli, E. Manoury); Laboratoire de Génie Chimique, Université de Toulouse, CNRS, INPT, UPS, 4 Allée Emile Monso, BP 84234, 31432 Toulouse, France (C. Julcour).

E-mail addresses: rinaldo.poli@lcc-toulouse.fr (R. Poli), eric.manoury@ lcc-toulouse.fr (E. Manoury), carine.julcour@ensiacet.fr (C. Julcour).

1 Present address: NS3E, UMR 3208 ISL-CNRS-Unistra, Institut franco-allemand de recherches de Saint-Louis, 5 rue du Général Cassagnou, 68301 St. Louis, France.

2 Present address: Process Development Advanced Research, L'Oréal, Research \& Innovation, 30 bis, rue Maurice Berteaux, 95500 Le Thillay, France.

${ }^{3}$ Present address: Faculté de Pharmacie et Département de Chimie, Université de Montréal, CP 6128 Succursale Centre Ville, Montréal, QC H3C 3J7, Canada. stimulate intense research because of interest in developing an efficient transformation of the heavier $\alpha$-olefins. Rhodium catalysts afford a much higher selectivity in favor of the greater added value linear product than the more commonly used cobalt carbonyl catalyst, but costs incurred in the recovery and recycling of the expensive metal make this process prohibitive. Rh-catalyzed hydroformylation is implemented on a large scale only for the lighter olefins (propene, butene) leading to sufficiently volatile aldehyde product amenable to cost-effective distillation $[5,6]$.

An alternative approach is available through the aqueous biphasic Rhône-Poulenc/Ruhrchemie process where the rhodium catalyst is confined in the aqueous phase by binding to water-soluble triphenylphosphine trisulfonate (TPPTS) [7]. This approach allows inexpensive and efficient catalyst recovery by simple room temperature decantation. However, the reaction occurs at sufficient rate only for the lighter alkenes (once again, propene and butene) that have sufficient solubility in water where the reaction takes place [8]. For higher olefins with insufficient water solubility, mass transport severely limits the reaction rate, which can only slowly take place at the water/organic interface. Many stratagems have been explored to increase mass transport, homogenize the system 
or increase the interface area, such as the addition of organic cosolvents $[9,10]$, cyclodextrins $[11-14]$, polymer lattices $[15,16]$ or other surfactants [16-18], the use of thermomorphic solvent systems [19-21] or anchoring the metal catalyst to the hydrophobic part of surfactants that self-organize in micellar form [22-26].

We have recently introduced a new tool for application to the aqueous biphasic hydroformylation of higher olefins, consisting of the unimolecular equivalent of a self-assembled micelle [2729]. This architecture was synthesized through a convergent approach using reversible addition-fragmentation chain transfer (RAFT)-mediated emulsion polymerization [30] in a three-step "one pot" preparation [27]. For convenience, the molecular structure of the polymer is shown in Fig. 1. Such technique made use of the polymerization-induced self-assembly (PISA) phenomenon to produce diblock copolymer micelles of controlled size the core cross-linking of which could be quantitatively achieved in a final step. The advantage of these objects with respect to the corresponding micelles is to remove the excessive nanoreactor swelling and the micelle-free surfactant equilibrium, which are known to negatively affect the catalyst recovery process and the catalyst leaching. More specifically, the new tool is a core-shell polymeric nanoreactor where the amphiphilic diblock copolymer arms are all tied together by cross-linking at the hydrophobic chain ends. We have named this new type of polymer architecture a "corecross-linked micelle" or CCM. The hydrophobic blocks are functionalized with triphenylphosphine (TPP) ligands via incorporation of 4-diphenylphosphinostyrene (DPPS) as a comonomer to insure the catalyst binding and confinement within the polymer core, whereas the hydrophilic shell insures the nanoreactor confinement in the aqueous phase. The first application of these nanoreactors, symbolized as TPP@CCM, to the aqueous biphasic hydroformylation of 1-octene has demonstrated high activity [27]. A follow-up study has highlighted the efficient recycling and the weak contribution of mass transport kinetics to the reaction rate [29]. However, ICP-MS analysis of the recovered organic phase showed a metal leaching of ca. 2 ppm. Most intriguing, dynamic light scattering studies suggested that this leaching is related to transfer of the entire polymer scaffold to the organic product phase as larger agglomerates (coupled particles).

The particle-particle coupling process was proposed to occur via interpenetration leading to core-core contact, allowing the cores to be cross-linked by the metal complex, see Fig. 2. This is possible because the standard hydroformylation conditions impose the presence of a large fraction of free TPP sites $(\mathrm{P} / \mathrm{Rh}=4$ was used in most catalytic tests) [27-29]. Of interest for an understanding of the leaching mechanism, the combined DLS and ICP-MS studies indicated a direct correlation between the amount of lost metal and the extent of particle-particle coupling. We have therefore

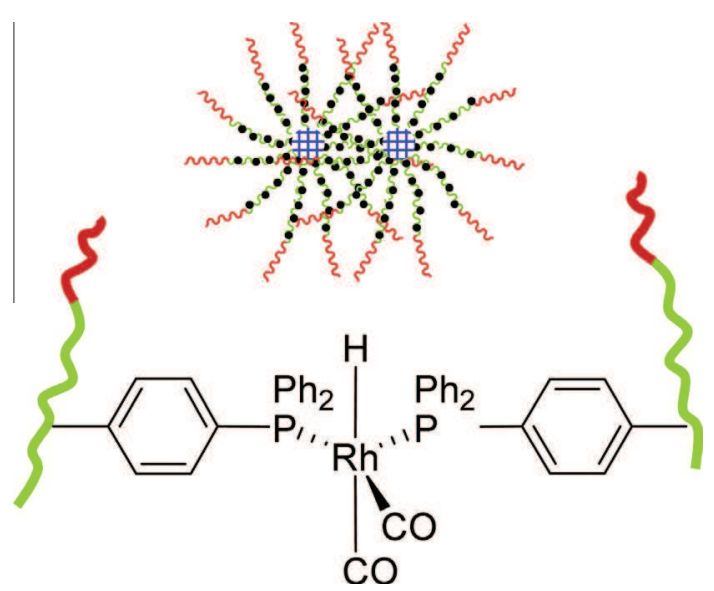

Fig. 2. Particle-particle coupling resulting from interpenetration and Rh-TPP coordination.

engineered a modified nanoreactor architecture, consisting of an entirely cross-linked phosphine-bearing hydrophobic core. This modification is expected to disfavor the reaction of a rhodium center with two phosphine ligands from different particles and should therefore lead to reduced interparticle coupling and metal leaching. The principle of stopping interpenetration by nanogel crosslinking was demonstrated by Hawker, Fréchet and coworkers who reported a successful one-pot tandem transformation with one acid-catalyzed and one base-catalyzed step, using a combination of acid- and base-functionalized nanogels [31]. In this contribution, we report the synthesis of a new nanogel (NG) nanoreactor and its application to 1-octene hydroformylation. As will be shown, the architecture modification indeed leads to a significant reduction of catalyst leaching.

\section{Experimental section}

\subsection{General}

All manipulations were performed under an inert atmosphere of dry argon by using Schlenk line techniques. Solvents were dried by standard procedures and distilled under argon prior to use. 4,4'-Azobis(4-cyanopentanoic acid) (ACPA, >98\%, Fluka), methacrylic acid (MAA, 99.5\%, Acros), poly(ethylene oxide) methyl ether methacrylate (PEOMA, $M_{\mathrm{n}}=950 \mathrm{~g} \mathrm{~mol}^{-1}$, Aldrich), di(ethylene glycol) dimethacrylate (DEGDMA, 95\%, Aldrich), 4diphenylphosphinostyrene (DPPS, 97\%, Aldrich), 1,3,5-trioxane (Aldrich, >99\%), acetylacetonatodicarbonyl rhodium(I), ([Rh(acac)

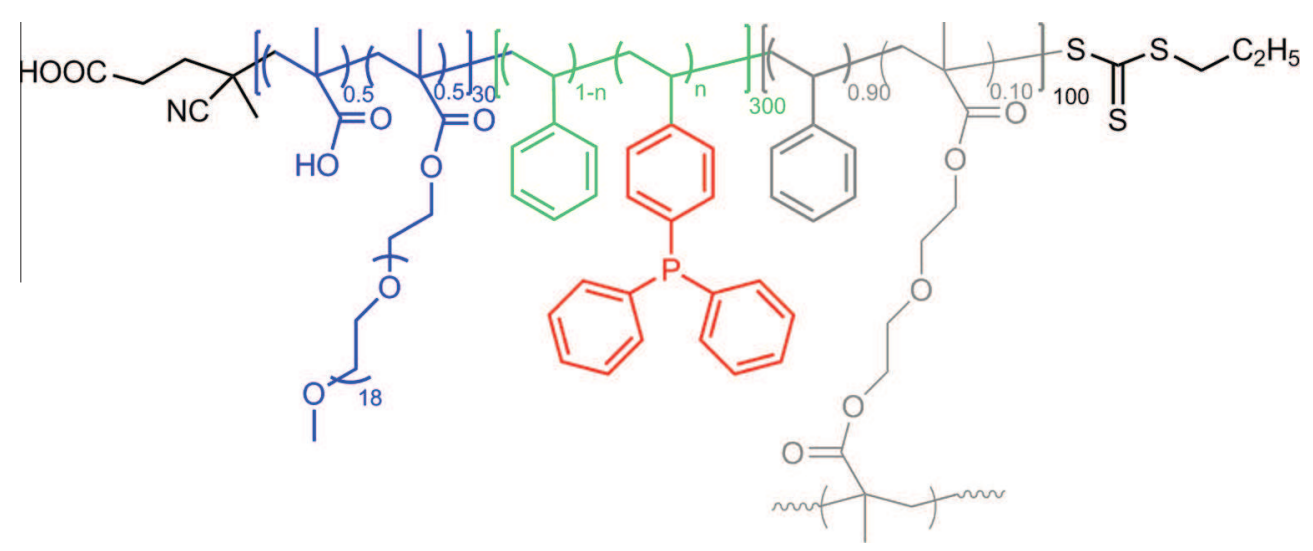

Fig. 1. Molecular structure of TPP@CCM. 
$(\mathrm{CO})_{2}$ ], 99\% Strem), $n$-decanal (>96\%, Alfa Aesar) and 1-octene (99\%, Acros) were used as received. Carbon monoxide and dihydrogen were obtained from Linde Gas (with purity $\geqslant 99.995 \%$ ). Styrene (S, 99\%, Acros) was purified by passing through a column of active basic aluminum oxide to remove the stabilizer. The RAFT agent 4cyano-4-thiothiopropylsulfanyl pentanoic acid (CTPPA) [32] was synthesized according to the published procedures. Latexes of core cross-linked nanoparticles functionalized by triphenylphosphine (TPP@CCM) were prepared as recently described [27]. The characteristics of the used latexes are summarized in Table 1 . They were diluted in ultrapure water for the catalytic tests.

\subsection{Characterization techniques}

\subsubsection{NMR}

${ }^{1} \mathrm{H}$ NMR and ${ }^{31} \mathrm{P}$ NMR spectra were recorded in $5 \mathrm{~mm}$ diameter tubes at $297 \mathrm{~K}$ in $\mathrm{D}_{2} \mathrm{O}$ using a Bruker Avance 400 spectrometer. ${ }^{1} \mathrm{H}$ chemical shifts were determined using the residual peak of deuterated solvent as internal standard and are reported in ppm $(\delta)$ relative to tetramethylsilane. ${ }^{31} \mathrm{P}$ chemical shifts are reported relative to external $85 \% \mathrm{H}_{3} \mathrm{PO}_{4}$. For the $\mathbf{C C M}$ characterization, the chemical shift scale was calibrated on the basis of the solvent peak $(\delta 2.50$ for DMSO, 4.79 for $\mathrm{D}_{2} \mathrm{O}$ ), and 1,3,5-trioxane was used as an integration reference $(\delta 5.20)$.

\subsubsection{SEC}

Size exclusion chromatography measurements were carried out in THF (with butylhydroxytoluene (BHT) as a flow rate marker) at $20{ }^{\circ} \mathrm{C}$ with a flow rate of $1.0 \mathrm{~mL} \mathrm{~min}^{-1}$. All polymers were analyzed at a concentration around $5 \mathrm{mg} \mathrm{mL}^{-1}$ after filtration through a $0.45 \mu \mathrm{m}$ pore-size membrane. The separation was carried out on a precolumn and three columns in series (type Styragel HR1/ HR3/HR4) with coupled multi-angle diffusion light scattering (Mini Dawn TriStar Wyatt) and refractometer (Wyatt Optilab Rex) detectors. The average molar masses (number-average molar mass $M_{n}$ and weight-average molar mass $M_{w}$ ) and the molar mass dispersity $\left(\nexists=M_{w} / M_{n}\right)$ were derived from the RI signal by a calibration curve based on poly(methyl methacrylate) standards.

\subsubsection{DLS}

The intensity-average diameters of the latex particles $\left(D_{z}\right)$ and the polydispersity index (PDI) were measured at $25^{\circ} \mathrm{C}$ on a Malvern Zetasizer NanoZS. After filtration through a $0.45 \mu \mathrm{m}$ poresize membrane, deionized water or THF was used to dilute the latex sample. Solutions were analyzed without further filtration to ensure that undesired populations were not removed. Data were analyzed by the general-purpose non-negative least squares (NNLS) method. The typical accuracy for these measurements was $10-15 \%$

\subsubsection{TEM}

The morphological analysis of the copolymer nano-objects was performed with a Philips CM120 transmission electron microscope operating at $80 \mathrm{kV}$ (Centre Technologique des Microstructures $(\mathrm{CT} \mu)$, plateforme de l'Université Claude Bernard Lyon 1, Villeurbanne, France) or a JEOL JEM 1011 transmission electron microscope equipped with $100 \mathrm{kV}$ voltage acceleration and tungsten filament (Service Commun de Microscopie Electronique TEMSCAN, Centre de Microcaractérisation Raimond Castaing, Toulouse, France). Diluted latex samples were dropped on a formvar/ carbon-coated copper grid and dried under vacuum.

\subsubsection{GC/FID}

At the end of the hydroformylation tests, the concentrations of reactant and products were measured in the organic phase using a Thermo Fisher Trace GC 2000 chromatograph equipped with a flame ionization detector (FID) and using helium as carrier gas. Separation was performed on a CP-Wax 52 CB capillary column (25 m $\times 0.25 \mathrm{~mm} ; 0.2 \mu \mathrm{m}$ film thickness). An internal calibration method was used by adding a precise quantity of anisole (99\%, Fluka) to the sample before dilution with diethyl ether $(\geqslant 99.8 \%$, Sigma-Aldrich). The response factors were determined by analysis of standard solutions of 1 -octene and $n$-nonanal (97\%, Alfa Aesar). The peak assignment was assisted by a separate GC-MS analysis on a Trace GC 2000 PolarisQ chromatograph.

\subsubsection{ICP/MS}

High resolution ICP/MS was used to quantify the rhodium catalyst leaching in the organic phase. Two different procedures were successively applied. In the first one, the recovered organic phase was diluted with ultrapure water using a $10^{5}$ volumetric dilution factor, high enough to insure complete dissolution. To eliminate matrix effects, rhodium standards were prepared in the same way by starting with solutions of $\left[\mathrm{Rh}(\mathrm{acac})(\mathrm{CO})_{2}\right]$ in $n$-decanal. The resulting aqueous phase was analyzed on a Thermo Scientific Element XR instrument. In the second method (performed by Antellis, Toulouse), the organic samples were mineralized by microwave-assisted acid digestion (Milestone Ultrawave) and the resulting acid solutions were diluted 250 -fold prior to analysis on a Thermo Electron Series X2 instrument. In both cases, the relative standard deviation on the measurements was less than $5 \%$ and the two techniques were found to match within a $25 \%$ deviation range.

\subsection{Preparation of TPP@NG-1 latex}

2.3.1. Step 1: Preparation of the $\mathrm{HOOCCH}_{2} \mathrm{CH}_{2} \mathrm{C}(\mathrm{CN})(\mathrm{Me})-\left(\mathrm{MA} \mathrm{A}_{15}-\mathrm{CO}-\right.$ $\left.\mathrm{PEOMA}_{15}\right)-S C(\mathrm{~S}) \mathrm{SPr}$ macroRAFT agent in water

The procedure was the same as that described previously [27] for the synthesis of core-cross-linked micelles, using $0.02 \mathrm{~g}$ $(0.0722 \mathrm{mmol})$ of CTPPA, $0.096 \mathrm{~g}(1.12 \mathrm{mmol})$ of MAA, $1.04 \mathrm{~g}$

Table 1

Polymer latexes used in this study. ${ }^{\text {a }}$

\begin{tabular}{|c|c|c|c|c|c|c|}
\hline & \multirow[t]{2}{*}{$x$ (DPPS) } & \multicolumn{2}{|c|}{$D_{z}(\mathrm{~nm}) / \mathrm{PDI}$} & \multirow[t]{2}{*}{ Solid content (\%) } & \multirow[t]{2}{*}{ [DPPS] $\left(\mathrm{mol} \mathrm{L}^{-1}\right)$} & \multirow[t]{2}{*}{ Ref. } \\
\hline & & $\mathrm{H}_{2} \mathrm{O}$ & THF & & & \\
\hline TPP@M & 30 & $72 / 0.21$ & - & 26.5 & 0.130 & {$[26]$} \\
\hline TPP@CCM-1 & 15 & $100 / 0.28$ & $160 / 0.07$ & 25.5 & 0.059 & [28] \\
\hline ТPР@ССM-2 & 30 & $79 / 0.18$ & $175 / 0.28$ & 27.3 & 0.128 & [26] \\
\hline ТPP@СCM-3 & 75 & $73 / 0.09$ & $235 / 0.20$ & 27.4 & 0.286 & [28] \\
\hline TPP@NG-1 & 15 & $90 / 0.20$ & $150 / 0.10$ & 20.5 & 0.054 & This work \\
\hline TPP@NG-2 & 30 & $87 / 0.14$ & $130 / 0.05$ & 32.1 & 0.145 & This work ${ }^{\mathrm{b}}$ \\
\hline
\end{tabular}

a TPP@M: $\quad \mathrm{HOOCCH}_{2} \mathrm{CH}_{2} \mathrm{C}(\mathrm{CN})(\mathrm{Me})-\left[\mathrm{MAA}_{15}-\mathrm{Co}-\mathrm{PEOMA}{ }_{15}\right]-b-\left[\mathrm{S}_{270}-\mathrm{Co}-(\mathrm{DPPS})_{30}\right]-\mathrm{SC}(\mathrm{S}) \mathrm{SPr} ; \quad$ TPP@CCM: $\quad \mathrm{HOOCCH}_{2} \mathrm{CH} \mathrm{C}_{2}(\mathrm{CN})(\mathrm{Me})-\left[\mathrm{MAA}{ }_{15}-\mathrm{CO}-\mathrm{PEOMA} \mathrm{A}_{15}\right]-b-\left[\mathrm{S}_{(300-x)}-\mathrm{CO}-\right.$

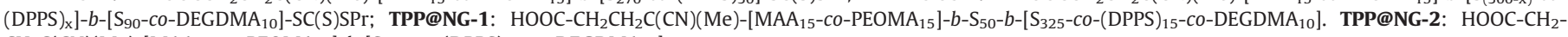
$\mathrm{CH}_{2} \mathrm{C}(\mathrm{CN})(\mathrm{Me})-\left[\mathrm{MAA}_{15}-\mathrm{Co}-\mathrm{PEOMA}_{15}\right]-b-\left[\mathrm{S}_{360} \text {-Co-(DPPS }\right)_{30}$-co-DEGDMA 10$]$.

b The existence of this polymer and its catalytic application have been previously mentioned [33]. 
(1.10 mmol) of PEOMA and $50 \mu \mathrm{L}$ of a stock solution containing $4 \mathrm{mg}$ of ACPA ( $0.0143 \mathrm{mmol})$ in $4.93 \mathrm{~mL}$ of water. The molar mass was determined by size exclusion chromatography (SEC) in THF (experimental $M_{\mathrm{n}}=15,600 \mathrm{~g} \mathrm{~mol}^{-1} ; D=1.15$ ).

\subsubsection{Step 2: Preparation of nanogel}

During Step 1, a biphasic solution of $\mathrm{S}(0.39 \mathrm{~g}, 3.7 \mathrm{mmol})$ and the ACPA stock solution $(50 \mu \mathrm{L}$ containing $4 \mathrm{mg}$ of ACPA, $0.014 \mathrm{mmol}$ ) were purged for $45 \mathrm{~min}$ with an argon stream at $0{ }^{\circ} \mathrm{C}$. This solution was quickly injected into the reaction flask, after the completion of Step 1, under argon at $80^{\circ} \mathrm{C}$. After $3 \mathrm{~h}$ of stirring, the polymerization was quenched by immersion of the flask into iced water. Then $\mathrm{S}(3 \mathrm{~g}, 28.8 \mathrm{mmol})$, DPPS (0.39 g, $1.35 \mathrm{mmol})$, DEGDMA $(0.21 \mathrm{~g}, 0.87 \mathrm{mmol})$ and $50 \mu \mathrm{L}$ of the ACPA stock solution (4 mg of ACPA, $0.014 \mathrm{mmol}$ ) and $15 \mathrm{~g}$ of deionized water were added. The mixture was purged for $1 \mathrm{~h}$ with argon at $0^{\circ} \mathrm{C}$, and the flask was then placed in an oil bath thermostated at $80^{\circ} \mathrm{C}$. After $3 \mathrm{~h}$, a $0.5 \mathrm{~mL}$ sample was withdrawn for analysis and the polymerization was quenched by immersion of the flask in iced water. The overall conversion of S and DEGDMA (99\%) was determined by ${ }^{1} \mathrm{H}$ NMR in THF- $d_{8}$ and that of DPPS (100\%) was measured by ${ }^{31} \mathrm{P}$ NMR in THF- $d_{8}$. DLS: $D_{\mathrm{h}}=90 \mathrm{~nm}(\mathrm{PDI}=0.2)$ in $\mathrm{H}_{2} \mathrm{O}, 150 \mathrm{~nm}(\mathrm{PDI}=0.10)$ in THF.

\subsection{Preparation of TPP@NG-2 latex}

Step 1 was carried out as described above for the synthesis of TPP@NG-1, during which time a mixture of S (2.196 g, $21 \mathrm{mmol})$, DPPS (0.596 g, $2.01 \mathrm{mmol})$, DEGDMA (0.176 g, $0.69 \mathrm{mmol}), 50 \mu \mathrm{L}$ of the ACPA stock solution ( $4 \mathrm{mg}$ of ACPA, $0.014 \mathrm{mmol}$ ) and deionized water $(3.8 \mathrm{~g}$ ) was purged for $45 \mathrm{~min}$ with an argon stream at $0{ }^{\circ} \mathrm{C}$. This biphasic solution was quickly injected into the reaction flask, after the completion of Step 1, under argon at $80^{\circ} \mathrm{C}$. After $3 \mathrm{~h}$ of stirring, the polymerization was quenched by immersion of the flask into iced water. The overall conversion of $\mathrm{S}$ and DEGDMA (99\%) was determined by gravimetric analysis and that of DPPS (100\%) was measured by ${ }^{31} \mathrm{P}$ NMR in THF- $d_{8}$. DLS: $D_{\mathrm{h}}=87-$ $\mathrm{nm}(\mathrm{PDI}=0.14)$ in $\mathrm{H}_{2} \mathrm{O}, 130 \mathrm{~nm}(\mathrm{PDI}=0.05)$ in THF.

2.5. General procedure for the phosphine ligand complexation to [Rh $\left.(\operatorname{acac})(\mathrm{CO})_{2}\right]$

The [Rh(acac)(CO)(TPP@NG)] latex (100\% Rh loading to the phosphine functions) was prepared as described previously for the analogous [Rh(acac)(CO)(TPP@CCM)] [27] by adjusting the amount of precursor $\left[\mathrm{Rh}(\mathrm{acac})(\mathrm{CO})_{2}\right]$ complex to a slight excess (ca. 1.01 equiv) relative to the amount of phosphine functions as detailed in Table $1 .{ }^{31} \mathrm{P}\left\{{ }^{1} \mathrm{H}\right\}$ NMR $\left(162 \mathrm{MHz}, \mathrm{CDCl}_{3}, 298 \mathrm{~K}\right): \delta 47.6$ (d, $J=175 \mathrm{~Hz}$ ).

\subsection{Biphasic hydroformylation catalysis}

A Hastelloy C276 autoclave $(290 \mathrm{~mL})$ equipped with a gas inducing stirrer was used for the hydroformylation experiments. During their preparation, careful attention was paid to prevent phosphine oxidation, as detailed in the experimental procedure described below.

\subsubsection{Preparation of the catalytic phase}

The as-synthesized latex (cf. Table 1) was first sonicated during $5 \mathrm{~min}$ prior to sampling the required amount $(0.65 \mathrm{mmol}$ of $\mathrm{P})$. This aliquot was diluted to $25 \mathrm{~mL}$ in a Schlenk flask containing deoxygenated ultrapure water (after three cycles of evacuation and nitrogen bubbling). Then the aqueous phase was stirred at $1200 \mathrm{rpm}$ under nitrogen atmosphere for $15 \mathrm{~min}$. Oxygen-free $n$ decanal $(3 \mathrm{~mL}$ ) was added to the aqueous phase to partly swell the latex particles and the colloidal suspension was further stirred at $1200 \mathrm{rpm}$ during $15 \mathrm{~min}$. At the same time, $0.16 \mathrm{mmol}$ of [Rh (acac)(CO $)_{2}$ ] was dissolved into $3 \mathrm{~mL}$ of $n$-decanal under a nitrogen atmosphere and the solution was stirred $15 \mathrm{~min}$ at $500 \mathrm{rpm}$, then sonicated for $3 \mathrm{~min}$ to ensure complete dissolution. The orange catalytic solution was added to the aqueous phase by a syringe under nitrogen and the mixture was stirred at $1200 \mathrm{rpm}$ for $3 \mathrm{~min}$.

\subsubsection{Preparation of the reactant phase}

$81.7 \mathrm{mmol}$ of 1 -octene was added into a Schlenk flask containing $56 \mathrm{~mL}$ of $n$-decanal. The solution was evacuated and placed under a nitrogen atmosphere. The molar fraction of 1-octene in the organic phase was 0.2 based on the whole organic phase i.e. $n$-decanal (including the fractions used to swell the objects and to dissolve the $\left[\mathrm{Rh}(\mathrm{acac})(\mathrm{CO})_{2}\right]$ precatalyst $)$ and 1-octene.

\subsubsection{Autoclave reaction}

The aqueous and organic phases were successively introduced into the reactor. The autoclave was then rapidly closed and flushed three times with $\mathrm{N}_{2}$ (15 bar). It was left under 15 bar of $\mathrm{N}_{2}$ for 10 min to check for leaks, and finally purged 3-4 times with syngas (equimolar $\mathrm{CO} / \mathrm{H}_{2}$ mixture prepared in a separated high pressure ballast tank, see Fig. S1). The mixture was heated to $90{ }^{\circ} \mathrm{C}$ under 2 bar of syngas at $250 \mathrm{rpm}$, well below gas self-induction, to generate the active catalytic species while hindering the reaction. Once the set temperature was reached (after about half an hour), the stirring was stopped. A first sample was taken to measure the initial reactant conversion, which was always found less than $2 \%$. The reactor was pressurized to 20 bar by a continuous feeding of syngas from the ballast tank through a gas pressure-reducing valve. Then, data acquisition was started and the stirring speed was set to the defined value (1200 rpm under standard operating conditions). Both temperature and pressure of the reactor and of the gas ballast were recorded on-line, in order to measure the instantaneous syngas consumption. After three hours of reaction, the stirring was stopped and a sample of the organic phase was withdrawn. The reactor was isolated from the ballast and the mixture was cooled under low stirring $(250 \mathrm{rpm})$ until it reached $40^{\circ} \mathrm{C}$. The stirring was stopped and the syngas replaced by nitrogen. The biphasic mixture was left to settle overnight under 5 bar of nitrogen before separation. The dynamics of the phase separation process was investigated separately, showing that the phase separation occurred in two successive stages: a first fast disengagement forming two distinct phases within $20 \mathrm{~min}$, followed by a much slower evolution within $3 \mathrm{~h}$. After $20 \mathrm{~min}$, the mixture consisted of an opaque aqueous phase containing the majority of the polymer particles and a translucent organic phase. In the final mixture, the organic phase had become almost transparent with a substantial decrease of the turbidity and increase of the transmittance. The detailed results of these experiments are given in the Supporting Information. All organic phase samples were analyzed by gas chromatography to quantify the linear to branched aldehyde ratios (1/ b), as well as the isomerization and hydrogenation by-products. The recovered organic phase was also examined for rhodium content by ICP/MS.

\section{Results and discussion}

\subsection{Synthesis and characterization of phosphine-functionalized nanogels, TPP@NG}

The present study makes use of phosphine-functionalized corecross-linked amphiphilic polymeric nanoreactors of two different kinds: core-cross-linked micelles (CCM) and nanogels (NG), both of them made by the RAFT polymerization technique, using 4- 
cyano-4-thiothiopropylsulfanyl pentanoic acid (CTPPA) as transfer agent and 4,4'-azobis(4-cyanopentanoic acid) (ACPA) as radical source and operating in water. The synthesis and characterization of the CCM have been previously reported [27-29]. The new NG polymers are quite similar in structure, size and composition to the $\mathbf{C C M}$, but differ from the latter in one important point: while in the CCM the phosphine functions are located on flexible linear arms which are cross-linked only at the very central part of the hydrophobic core, the phosphine functions in the NG are located inside the cross-linked part, which extends to almost the entire hydrophobic core (see Fig. 3). The different architectures are achieved by a different monomer feeding sequence.

The first step for both CCM and NG syntheses is the aqueous polymerization of a 50:50 mixture of methacrylic acid (MAA) and poly(ethylene oxide) methyl ether methacrylate (PEOMA), using 15 equivalents of each monomer per molecule of transfer agent. The polymerization is well controlled leading to the formation of the water soluble $\mathrm{HOOCCH}_{2} \mathrm{CH}_{2} \mathrm{C}(\mathrm{CN})(\mathrm{Me})-\left[\mathrm{MAA}_{15}-\mathrm{Co}-\mathrm{PEOMA}_{15}\right]-$ SC(S)SPr macroRAFT agent. For the synthesis of the TPP@CCM [27-29], the second step consists of the statistical copolymerization of styrene (S) and 4-diphenylphosphinostyrene (DPPS), which involves polymerization-induced self-assembly (PISA) to yield micelles (M), and is followed by final cross-linking via the controlled polymerization of a diethylene glycol dimethacrylate (DEGDMA) - styrene mixture [27,29]. For the synthesis of the new NG polymers, the functionalized monomer (DPPS), the DEGDMA cross-linker and the styrene "diluent" monomer were added simultaneously in the last step. For the synthesis of TPP@NG-1, well dispersed nanoparticles with narrow sizedistribution were obtained after a first short chain extension of the macroRAFT agent by styrene ( 50 equivalents per chain) leading to PISA. It was found that this intermediate chain extension helped avoid macrogelation in the final step.

All particles used in the present study (see Table 1) have the same relative amounts of hydrophilic, hydrophobic and crosslinking monomer molecules per transfer agent: 30 hydrophilic ones (15 MAA + 15 PEOMA) in step 1, 300 hydrophobic ones ( $S$ + DPPS) in step 2, and 100 additional ones (90 S + 10 DEGDMA) in step 3. They differ only in the relative DPPS content in the hydrophobic core $(15,30$ or 75 DPPS monomers per chain). The TPP@CCM-1 and TPP@NG-1 on one hand, and the TPP@CCM-2 and TPP@NG-2 on the other, have the same overall composition and differ only in the core architecture. For comparison purposes, we have also used the latex dispersion of the micelles resulting from step 2 with 30 DPPS monomers per chain, which will be referred to as TPP@M, see Table 1.

Transmission electron micrographs of the nanogels revealed that the particles have spherical shape, small and regular dimensions, and a relatively narrow size distributions, see Fig. 4. Diluted dispersions were analyzed by dynamic light scattering, see Fig. 5, affording the average size $\left(D_{z}\right)$ and polydispersity index (PDI) reported in Table 1 , which qualitatively agree with the dimensions visually observed by TEM. Note that all polymers have approximately the same size in water $\left(D_{z}\right.$ of $\left.70-100 \mathrm{~nm}\right)$, which increases significantly in THF where the core part becomes soluble (Table 1 ). The swelling factor, however, is significantly lower for the NG particles relative to the $\mathbf{C C M}$, as expected from the different crosslinking mode.

The NMR properties of the NG are very similar to those previously established for the corresponding CCM. Only the main points are recalled here, with the relevant characterization spectra available in the Supporting Information. The large dimensions and insolubility of the particle core in water make this part of the polymer invisible by NMR. Thus, the ${ }^{1} \mathrm{H}$ NMR spectrum of TPP@NG in $\mathrm{D}_{2} \mathrm{O}$ reveals only the resonances of the PEO chains (Fig. S2), while the ${ }^{31} \mathrm{P}$ NMR spectra are silent. The outer shell backbone protons (MAA $\mathrm{CH}_{3}, \mathrm{CH}_{2}$ and $\mathrm{CH}$ protons and PEOMA backbone $\mathrm{CH}_{2}$ and $\mathrm{CH}$ protons) are also invisible, suggesting that they remain solidary with the hydrophobic core. All protons become visible, however, in THF- $d_{8}$ (Fig. S3) showing that the low cross-linking density confers sufficient mobility to the full macromolecule like for the corresponding more flexible $\mathbf{C C M}$. The core phosphine functions become

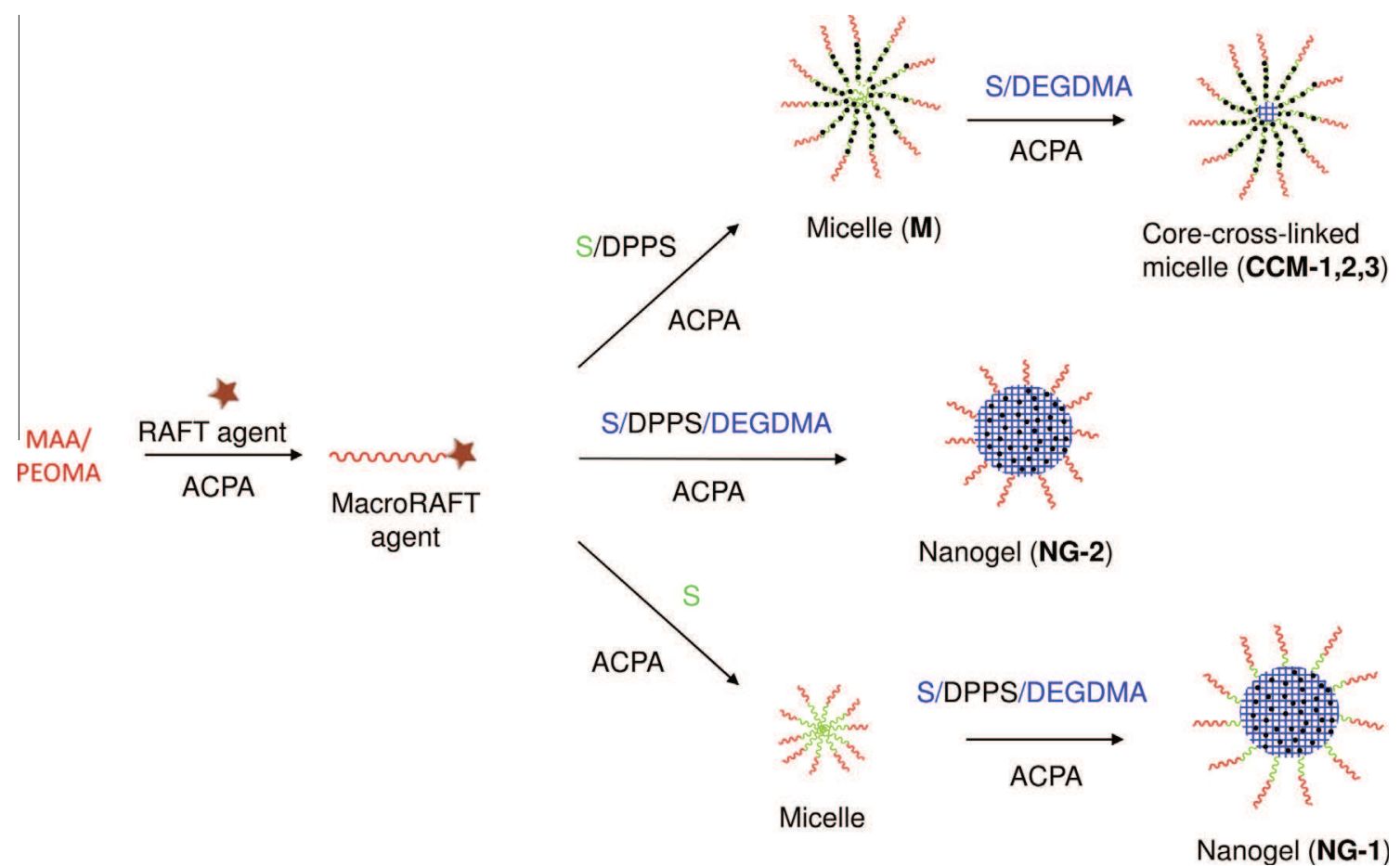

Fig. 3. Different architectures of the CCM and NG particles. 


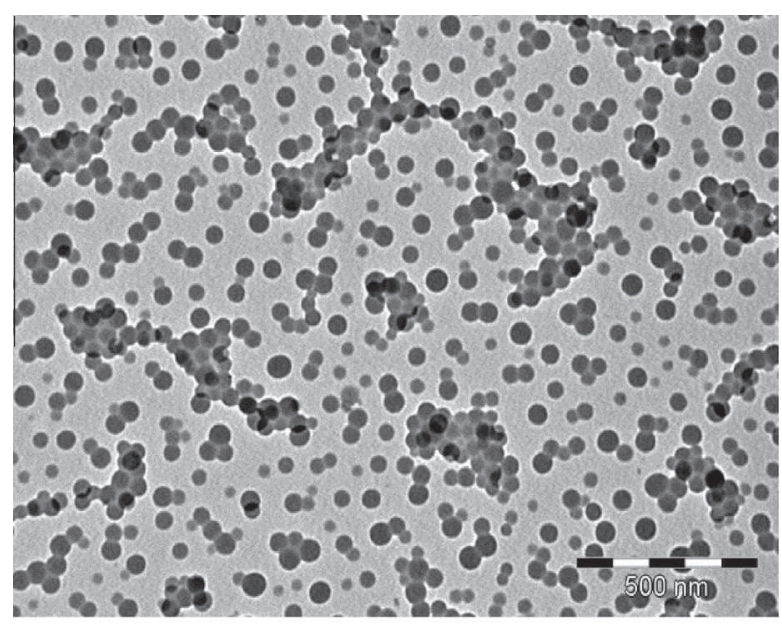

(A)

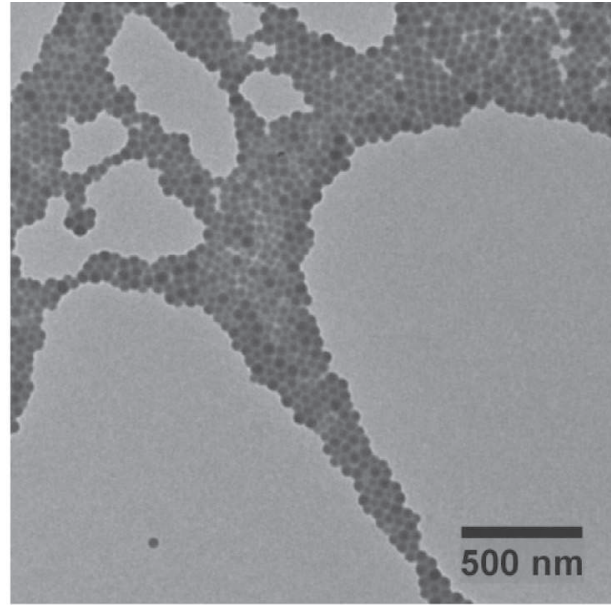

(B)

Fig. 4. TEM image of (A) TPP@NG-1 and (B) TPP@NG-2.

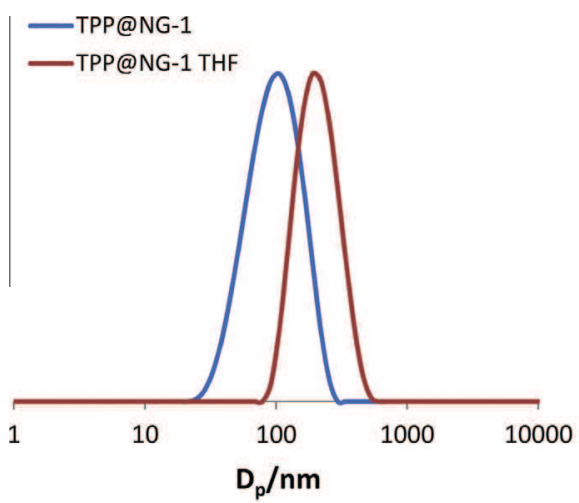

(A)

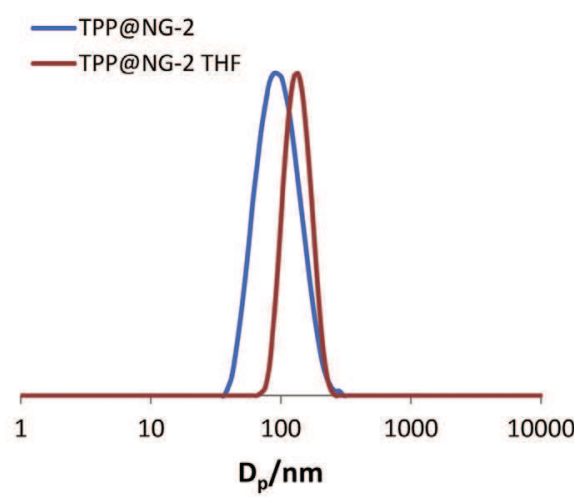

(B)

Fig. 5. DLS analysis in water and THF of (A) TPP@NG-1 and (B) TPP@NG-2.

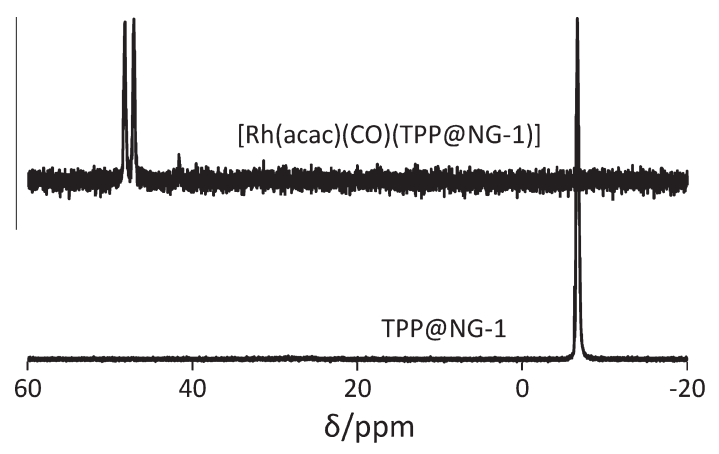

Fig. 6. ${ }^{31} \mathrm{P}\left\{{ }^{1} \mathrm{H}\right\}$ NMR spectra of TPP@NG-1 in water after swelling with toluene, before and after loading (100\%) with $\left[\mathrm{Rh}(\mathrm{acac})(\mathrm{CO})_{2}\right]$.

visible in the ${ }^{31} \mathrm{P}\left\{{ }^{1} \mathrm{H}\right\}$ NMR spectrum with a single resonance at $\delta$ -8.3 , which is identical to that obtained under the same conditions for TPP@CCM [27].

Addition of organic solvents (toluene, chloroform) that are immiscible with water but compatible with the particle hydrophobic core results in nanoparticle swelling: the resonances of the core proton and $\mathrm{P}$ nuclei become observable in the ${ }^{1} \mathrm{H}$ and ${ }^{31} \mathrm{P}$ NMR spectra (Figs. S4 and S5). Similar to the behavior previously reported for the CCM particles [27,28], the outer shell PEO resonances are split into two sets when the NG is swollen by toluene: a sharper one associated with the more mobile PEO chain in an aqueous environment and a broader one associated with less mobile chains folded back into the hydrophobic core. Line deconvolution of the stronger PEO methylene resonance (see Fig. S6) yields ratios for the water-solvated and toluene-solvated PEO chains of a 20.3:79.7 for TPP@NG-1, showing that toluene swelling compatibilizes the major fraction of the PEO chains in the NG particles with the hydrophobic core. A similar result was obtained for the related CCM particles (e.g. a 30.3:69.7 distribution for TPP@CCM-2 [27]). Rough integration of the free toluene aromatic and methyl resonances (accuracy is limited because of overlap with the broader polymer resonances) yields an estimate of 520600 molecules of toluene per chain being incorporated in swollen TPP@NG-1 (cf. 770-950 for TPP@CCM-2 [27]). The two estimates in each case correspond to the integration of the aromatic and methyl proton resonances. Upon swelling with chloroform, on the other hand, the PEO chains remain essentially completely confined in the aqueous environment (Fig. S4). This behavior is, once again, identical to that of the $\mathbf{C C M}$. Integration of the ${ }^{1} \mathrm{H}$ NMR resonance suggests incorporation of ca. 930 chloroform molecules per chain in the TPP@NG-1 core ( $c f$. ca. 2000 for TPP@CCM-2). The relatively low cross-linking density does not introduce dramatic constraints to significantly alter the swelling capacity or the chain mobility and the partition of the shell PEO chains between the aqueous phase and the toluene-swollen core in the NG relative to the CCM. 


\subsection{Metal coordination inside the nanoreactors}

Treating the toluene-swollen NG particles with a toluene solution of $\left[\mathrm{Rh}(\mathrm{acac})(\mathrm{CO})_{2}\right]$ (1 equiv per $\mathrm{P}$ atom) results in rapid transfer of the metal complex to the macromolecule core and coordination to the phosphine functions by CO ligand substitution to form [Rh(acac)(CO)(TPP@NG)] (Eq. (1)), as signaled by the replacement of the NMR ${ }^{31} \mathrm{P}$ resonance of the free phosphine with that of the Rh-ligated phosphine at $\delta 47.6(\mathrm{~d}, J=175 \mathrm{~Hz})$, see Fig. 6 for TPP@NG-1 (the TPP@NG-2 shows identical behavior). This resonance corresponds closely in chemical shift and Rh coupling to that of the corresponding molecular compound $[\mathrm{Rh}(\mathrm{acac})(\mathrm{CO})$ $\left.\left(\mathrm{PPh}_{3}\right)\right]\left(\delta 48.6, J_{\mathrm{PRh}}=179.7 \mathrm{~Hz}\right)$ [34]. It is also essentially identical to that previously reported for the $[\mathrm{Rh}(\mathrm{acac})(\mathrm{CO})]$-loaded TTP@CCM [27]. By analogy with the behavior described for the CCM, loading with only $1 / 2$ equivalents of metal complex, therefore leaving $50 \%$ of the phosphine functions non-coordinated, yields silent spectra because the rate of the self-exchange process (Eq. (2)) results in resonance coalescence at room temperature $[27,28]$.

$\left[\mathrm{Rh}(\mathrm{acac})(\mathrm{CO})_{2}\right]+\mathrm{TPP} @ \mathrm{NG} \rightarrow[\mathrm{Rh}(\mathrm{acac})(\mathrm{CO})(\mathrm{TPP} @ \mathrm{NG})]+\mathrm{CO}$

$$
\begin{aligned}
& {[\mathrm{Rh}(\mathrm{acac})(\mathrm{CO})(\mathrm{TPP} @ \mathrm{NG})]+\mathrm{TPP} @ \mathrm{NG} \rightleftarrows \mathrm{TPP} @ \mathrm{NG}} \\
& \quad+[\mathrm{Rh}(\mathrm{acac})(\mathrm{CO})(\mathrm{TPP} @ \mathrm{NG})]
\end{aligned}
$$

\subsection{Catalytic performance of TPP@NG in the hydroformylation of 1- octene}

The new TPP@NG latexes were tested for the biphasic Rhcatalyzed hydroformylation of 1-octene under the same operating conditions previously used $[27,29]$ for the analogous TPP@CCM catalyst supports: molar ratio of 1 -octene/Rh and $\mathrm{P} / \mathrm{Rh}$ respectively set to 500 and 4,20 bar of syngas pressure, $90^{\circ} \mathrm{C}, 20 \mathrm{~mol} . \%$ of 1 octene in $n$-decanal, and volume ratio of organic mixture to aqueous latex suspension set to 3 . The $\mathrm{pH}$ of the aqueous phase was not adjusted and its value, measured after the reaction, was about 4 . Table 2 compares the TPP@NG performances with those of the related TPP@CCM in terms of activity, 1/b selectivity and Rh leaching. In all the investigated cases, no hydrogenation and low isomerization (about $5 \%$ ) were observed.

Thanks to the ballast pressure recording, the gas consumption could be calculated at any time of the reaction. For the calculation of the initial reaction rate, a compromise on the considered time interval had to be sought so as to keep a low 1-octene conversion $(<20 \%)$ while minimizing the effect of pressure fluctuations on the linear regression. The sensibility study showed that a variation of $10 \%$ in the TOF value should not be considered as significant and the uncertainty on the $1 / \mathrm{b}$ ratio was estimated as ca. $\pm 5 \%$. Therefore, the comparisons between the repeat experiments for TPP@NG-1 (entries 1b and 1c) and for TPP@CCM-2 (entries 4a and 4b) show good reproducibility.

\subsubsection{Comparison of different nanoreactor architectures}

Going from M to CCM (cross-linking the terminal parts of the hydrophobic segments) results in ca. $20 \%$ reduction of the initial turnover frequency (TOF) (cf. entries 4a/b and entry 6 of Table 2). Further mobility reduction in NG, given the catalytic site embedding inside the cross-linked network, results in reduced accessibility to the catalytic complexes and hence further TOF reduction, but only by about $20 \%$ regardless of the degree of functionalization. The TOF mean values at $1200 \mathrm{rpm}$ are ca. 600 vs. $695 \mathrm{~h}^{-1}$ (TPP@NG-1, entries 1b/c, vs. TPP@CCM-1, entry 3) and 379 vs. $457 \mathrm{~h}^{-1}$ (TPP@NG-2, entry 2, vs. TPP@CCM-2, entries 4a/b). The $1 / b$ selectivity is of the same order of magnitude for the different architectures, but no clear trend can be identified. The most striking effect concerns the Rh leaching to the organic phase, with a continuous decrease following the scaffold stiffening, as will further be commented.

\subsubsection{Effect of the degree of functionalization}

For the TPP@CCM-supported catalyst [29], a phosphine content increase was found to substantially lower the initial reaction rate (Table 2, entries 3-5). This trend is confirmed in the case of TPP@NG: increasing the DPPS co-monomer in the hydrophobic core from $5 \%$ to $10 \%$ mol. reduces TOF by ca. $35 \%$ for both objects. A possible rationalization of this phenomenon lies in the steric hindrance caused by the higher phosphine density, although this phenomenon would be expected to be accentuated in the nanogel. On the other hand, a higher functionalization degree also means a higher density of Rh within the objects and possibly the formation of inactive dimeric Rh species [35].

Whereas the $1 / b$ ratio appears to improve upon increasing the phosphine content in TPP@CCM (entries 3, 4a/b and 5), it is not significantly affected by the same modification in TPP@NG (entries $1 \mathrm{~b} / \mathrm{c}$ and 2 ). At higher DPPS:S ratio, the ligand entrapping within

Table 2

\begin{tabular}{|c|c|c|c|c|c|c|c|}
\hline Entry & Investigated ligand & Stirring speed (rpm) & Initial rate $\left(\mathrm{kmol} \mathrm{m}_{\text {paq }}^{-3} \mathrm{~s}^{-1}\right)^{\mathrm{b}}$ & $\mathrm{TOF}_{\max }\left(\mathrm{h}^{-1}\right)^{\mathrm{b}}$ & $1 / b^{c}$ & \multicolumn{2}{|c|}{$\begin{array}{l}\text { Rh leaching } \\
\left(\mathrm{mg} \mathrm{L}_{\text {porg }}^{-1}\right)^{\mathrm{d}}\end{array}$} \\
\hline 1a & TPP@NG-1 & 1000 & $1.1 \cdot 10^{-3}$ & 617 & 3.6 & - & 1.0 \\
\hline 1b & & 1200 & $1.1 \cdot 10^{-3}$ & 567 & 3.6 & - & 1.2 \\
\hline 1c & & 1200 & $1.2 \cdot 10^{-3}$ & 632 & 3.6 & - & 1.0 \\
\hline 1d & & 1400 & $9.9 \cdot 10^{-4}$ & 525 & 3.5 & - & 0.4 \\
\hline 1e & & 1600 & $1.1 \cdot 10^{-3}$ & 611 & 3.5 & - & 0.8 \\
\hline $2^{\mathrm{e}}$ & TPP@NG-2 & 1200 & $7.0 \cdot 10^{-4}$ & 378 & 3.6 & 0.6 & 0.8 \\
\hline $3^{f}$ & ТРP@ССM-1 & 1200 & $1.3 \cdot 10^{-3}$ & 695 & 3.3 & 1.8 & - \\
\hline $4 a^{g}$ & ТРP@СCM-2 & 1200 & $8.0 \cdot 10^{-4}$ & 441 & 5.0 & 2.0 & 1.8 \\
\hline $\mathbf{4} \mathbf{b}^{\mathrm{f}}$ & & 1200 & $8.5 \cdot 10^{-4}$ & 473 & 4.4 & 2.5 & - \\
\hline $4 c^{f}$ & & 1400 & $1.0 \cdot 10^{-3}$ & 557 & 3.4 & 6.5 & - \\
\hline $\mathbf{4 d}^{\mathrm{f}}$ & & 1600 & $1.0 \cdot 10^{-3}$ & 579 & 3.5 & 11.6 & - \\
\hline $\mathbf{5}^{\mathrm{f}}$ & ТPР@ССМ-3 & 1200 & $3.5 \cdot 10^{-4}$ & 191 & 4.7 & 1.4 & - \\
\hline $6^{g}$ & TPP@M & 1200 & $1.0 \cdot 10^{-3}$ & 560 & 3.8 & 7.2 & 6.0 \\
\hline
\end{tabular}

Results of the biphasic hydroformylation of 1-octene. ${ }^{a}$

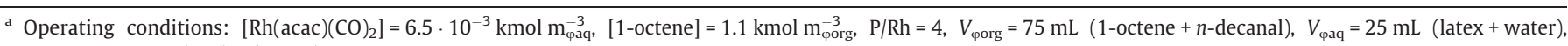
$T=363 \mathrm{~K}, P_{\text {syngas }}=20$ bar $\left(\mathrm{CO} / \mathrm{H}_{2}=1\right)$.

${ }^{\mathrm{b}}$ Initial reaction rate (with respect to non-swollen aqueous phase) and corresponding turnover Frequency calculated from syngas consumption.

c Linear to branched aldehyde ratio determined from the GC/FID analysis of the final sample.

d $\mathrm{Rh}$ concentration in the organic phase measured by ICP/MS (left: dilution method; right: mineralization method).

e These results have also been previously mentioned in Ref. [33].

f,g Results recalled from Refs. [29,27], respectively. 
the cross-linked structure might hamper the formation of catalytic species with a higher number of coordinated phosphine, known to be more regioselective. For both objects, the functionalization degree has no appreciable effect on the Rh leaching.

\subsubsection{Effect of stirring speed}

Since the Rh leaching was found to increase with a more vigorous stirring for the CCM-supported catalyst $[27,29]$ (1600 rpm vs. $1200 \mathrm{rpm}$, see entries $4 \mathrm{a}-\mathrm{d}$ ), the effect of this operating parameter was also examined for TPP@NG-1. Originally, the stirring speed was increased from 1200 to $1600 \mathrm{rpm}$ as a typical test to examine the possible presence of external mass transfer (especially gas absorption) on the measured reaction rates. This range was extended to $1000 \mathrm{rpm}$ for TPP@NG-1. The negligible variation of the measured TOF allows concluding on the absence of any significant mass transfer limitation on the reaction rate under the investigated conditions. On the other hand, increasing the stirring speed for the experiments with TPP@NG-1 (entries 1a-e) resulted not only in a lower $\mathrm{Rh}$ loss to the organic phase relative to the TPP@CCM samples, but also and most interestingly in similar levels of Rh loss for all experiments (nearly unchanged $\mathrm{Rh}$ content of about $1 \mathrm{ppm}$ in all the organic phases recovered after the reaction tests performed between 1000 and $1600 \mathrm{rpm}$ ). Namely, the stirring speed has a much smaller effect, if any, on the Rh leaching for the TPP@NG system.

As stated in the introduction, the DLS analysis of the recovered organic phase for the TPP@CCM experiments has shown light scattering consistent with the presence of polymeric nanoreactors and a correlation between the Rh loss and the particle size, suggesting the intervention of particle-particle coupling as shown in Fig. 1 and a higher transfer of the coupled particles to the organic phase. The architecture change from CCM to NG should naturally lead to less favorable interparticle coupling because of the physical impediment by the core cross-linking. This is indeed consistent with the lower leaching measured for the experiments with the TPP@NG. It is also consistent with a smaller effect of the stirring rate on the leaching level, if we assume that indeed coupled particles are transferred preferentially to the organic phase. The DLS measurements on the recovered organic phases for entries $1 \mathrm{a}-\mathrm{e}$ and 2 indeed showed the presence of particles, but the measurement was at the limit of the instrument sensitivity and did not afford reliable results to conclude on any effect of the stirring rate on the particle size. The residual leaching observed for the TPP@NGsupported catalyst may result from either residual transfer of the polymeric particles, even in the absence of interparticle coupling, or escape of part of the Rh catalyst from the polymer as a molecular species. Separately published coordination chemistry investigations with these nanoreactors and more specifically on the interparticle metal migration rate and mechanism strongly indicate that metal escape from the polymer core as a molecular species indeed occurs, although the extent of this loss could not be quantified [36]. The leaching mechanism and various strategies to further reduce it continue to be the object of our investigations.

\section{Conclusion}

Slight modification of the synthetic strategy of the earlier TPP@CCM macroligand has yielded a nanogel architecture offering a reduced catalyst leaching, without significant loss of activity or selectivity. Variation in the functionality degree of these objects was proven to mainly affect the TOF values. This paves the way toward further improvement of these nanoreactors owing to the flexibility of the PISA technique, which should allow anchoring bidentate ligands for a higher $\mathrm{l} / \mathrm{b}$ regioselectivity or tuning the hydrophilic shell functionalities for a better confinement in the aqueous phase. Particle interpenetration, previously identified as a possible aggravating factor for the catalyst loss into the organic phase, appears confirmed by the reduced ability of the nanogel structure to lead to interparticle coupling. Further improvements could be achieved by modifying the nanoparticle shell or the aqueous phase properties so as to promote electrostatic repulsion between particles. This will be examined in the forthcoming work.

\section{Acknowledgments}

We are grateful to the Agence Nationale de la Recherche (ANR) for support of this work through grant "BIPHASNANOCAT" (ANR11-BS07-025-01). Additional support from the Centre National de la Recherche Scientifique (CNRS) and from the Institut Universitaire de France (IUF) is also gratefully acknowledged. We thank J. L. Labat and M.L. Pern (LGC) for their technical support on the hydroformylation tests, and R. Mole (AIGEP) and V. Baylac (CIRIMAT) for their help on phase separation measurements.

\section{Appendix A. Supplementary material}

Supplementary data associated with this article can be found, in the online version, at http://dx.doi.org/10.1016/j.jcat.2016.07.023.

\section{References}

[1] M. Beller, B. Cornils, C.D. Frohning, C.W. Kohlpaintner, J. Mol. Catal. A 104 (1995) 17.

[2] P.W.N.M. van Leeuwen, C. Claver (Eds.), Rhodium Catalyzed Hydroformylation, vol. 22, Kluwer, Dordrecht, 2000.

[3] K.D. Wiese, D. Obst, in: M. Beller (Ed.), Catalytic Carbonylation Reactions, Springer, Berlin, 2006, p. 1.

[4] D. Steinborn, Fundamentals of Organometallic Catalysis, Wiley-VCH, Weinheim, 2011.

[5] R. Tudor, M. Ashley, Platinum Met. Rev. 51 (2007) 164.

[6] R. Tudor, M. Ashley, Platinum Met. Rev. 51 (2007) 116.

[7] C.W. Kohlpaintner, R.W. Fischer, B. Cornils, Appl. Catal. A 221 (2001) 219.

[8] O. Wachsen, K. Himmler, B. Cornils, Catal. Today 42 (1998) 373.

[9] R.M. Deshpande, P. Purwanto, H. Delmas, R.V. Chaudhari, Ind. Eng. Chem. Res. 35 (1996) 3927.

[10] P. Purwanto, R.M. Deshpande, R.V. Chaudhari, H. Delmas, J. Chem. Eng. Data 41 (1996) 1414.

[11] L. Leclercq, F. Hapiot, S. Tilloy, K. Ramkisoensing, J.N.H. Reek, P.W.N.M. van Leeuwen, E. Monflier, Organometallics 24 (2005) 2070

[12] S. Tilloy, G. Crowyn, E. Monflier, P.W.N.M. van Leeuwen, J.N.H. Reek, New J. Chem. 30 (2006) 377.

[13] L. Leclercq, H. Bricout, S. Tilloy, E. Monflier, J. Colloid Interf. Sci. 307 (2007) 481.

[14] F.X. Legrand, F. Hapiot, S. Tilloy, A. Guerriero, M. Peruzzini, L. Gonsalvi, E. Monflier, Appl. Catal. A 362 (2009) 62.

[15] K. Kunna, C. Müller, J. Loos, D. Vogt, Angew. Chem. Int. Ed. 45 (2006) 7289.

[16] H. Nowothnick, A. Rost, T. Hamerla, R. Schomacker, C. Muller, D. Vogt, Catal. Sci. Technol. 3 (2013) 600

[17] S.L. Desset, D.J. Cole-Hamilton, D.F. Foster, Chem. Commun. (2007) 1933.

[18] S.L. Desset, S.W. Reader, D.J. Cole-Hamilton, Green Chem. 11 (2009) 630.

[19] A. Behr, in: B. Cornils, W.A. Herrmann, I.T. Horvath, W. Leitner, S. Mecking, H. Olivier-Bourbigou, D. Vogt (Eds.), Multiphase Homogeneous Catalysis, vol. 1, Wiley-VCH, Weinheim, Germany, 2005, 2005, p. 327.

[20] J. Tijani, B. El Ali, Appl. Catal. A 303 (2006) 158.

[21] M.S. Shaharun, B.K. Dutta, H. Mukhtar, S. Maitra, Chem. Eng. Sci. 65 (2010) 273.

[22] O. Nuyken, P. Persigehl, R. Weberskirch, Macromol. Symp. 177 (2002) 163.

[23] M.T. Zarka, M. Bortenschlager, K. Wurst, O. Nuyken, R. Weberskirch, Organometallics 23 (2004) 4817.

[24] X.Z. Liu, H.M. Li, F.Z. Kong, J. Organomet. Chem. 664 (2002) 1.

[25] X. Liu, F. Kong, X. Zheng, Z. Jin, Catal. Commun. 4 (2003) 129.

[26] G.M. Pawar, J. Weckesser, S. Blechert, M.R. Buchmeiser, Beilstein J. Org. Chem. $6(28)(2010)$

[27] X. Zhang, A.F. Cardozo, S. Chen, W. Zhang, C. Julcour, M. Lansalot, J.F. Blanco, F. Gayet, H. Delmas, B. Charleux, E. Manoury, F. D’Agosto, R. Poli, Chem. Eur. J. 20 (2014) 15505

[28] S. Chen, A.F. Cardozo, C. Julcour, J.F. Blanco, L. Barthe, F. Gayet, B. Charleux, M. Lansalot, F. D'Agosto, H. Delmas, E. Manoury, R. Poli, Polymer 72 (2015) 327.

[29] A.F. Cardozo, C. Julcour, L. Barthe, J.F. Blanco, S. Chen, F. Gayet, E. Manoury, X. Zhang, M. Lansalot, B. Charleux, F. D’Agosto, R. Poli, H. Delmas, J. Catal. 324 (2015) 1 .

[30] W. Zhang, F. D’Agosto, O. Boyron, J. Rieger, B. Charleux, Macromolecules 44 2011) 7584.

[31] B. Helms, S.J. Guillaudeu, Y. Xie, M. McMurdo, C.J. Hawker, J.M.J. Fréchet, Angew. Chem. Int. Ed. Engl. 44 (2005) 6384. 
[32] T. Boursier, I. Chaduc, J. Rieger, F. D’Agosto, M. Lansalot, B. Charleux, Polym. Chem. 2 (2011) 355.

[33] R. Poli, S. Chen, X. Zhang, A. Cardozo, M. Lansalot, F. D’Agosto, B. Charleux, E. Manoury, F. Gayet, C. Julcour, J.F. Blanco, L. Barthe, H. Delmas, ACS Symp. Ser. 1188 (2015) 203.
[34] F. Bonati, G. Wilkinson, J. Chem. Soc. (1964) 3156.

[35] K.S. Ro, S.I. Woo, Appl. Catal. 69 (1991) 169.

[36] S. Chen, F. Gayet, E. Manoury, A. Joumaa, M. Lansalot, F. D’Agosto, R. Poli, Chem. Eur. J. (2016) 6302. 